\title{
Determinants of neonatal mortality in the largest international border of Brazil: a case-control study
}

\author{
Suzana de Souza ${ }^{1,3}$, Etienne Duim² and Fernando Kenji Nampo ${ }^{1,3^{*}}$ (D)
}

\begin{abstract}
Background: Foz do Iguassu is a Brazilian municipality located in the most populous international border of the country and provides medical care to foreigners. Neonatal mortality in the city is higher than Brazil's average and corresponds to $61 \%$ of all deaths in children under five. The current study aimed to identify the determinants of neonatal mortality in Foz do Iguassu.

Methods: In this case-control study, we analyzed all neonatal deaths occurred in Foz do Iguassu from 2012 to 2016. Birth and mortality data were extracted from two national governmental databases (SINASC and SIM). We extracted data on (i) maternal sociodemographic characteristics, (ii) pregnancy care, and (iii) newborn characteristics. Multiple logistic regression with the conceptual framework was applied to examine the factors associated with neonatal mortality.

Results: Most of the deaths occurred in the early neonatal period (65.9\%). The factors associated with neonatal death were fetal congenital anomaly (OR 22.49; Cl 95\% 7.44-67.95; $p=<0.001$ ); low birth weight (OR 17.15; Cl 95\% 8.56-34.37; $p=<0.001$ ), first minute Apgar score under 7 (OR 15.60; Cl 95\% 8.23-29.67; $p=<0.001$ ); zero to 3 prenatal appointments (OR 3.34; $\mathrm{Cl} 95 \%$ 1.28-8.73; $p=0.014$ ) and prematurity (OR 3.60; $\mathrm{Cl} 95 \%$ 1.87-7.11; $p=<$ 0.001 ).

Conclusion: The high rate of neonatal death in Foz do Iguassu is strongly associated with newborn characteristics and not associated with maternal sociodemographic characteristics. Thus, the health services in the Brazilian side of this international borders should be aware of the quality of the prenatal care and childbirth attention provided.
\end{abstract}

Keywords: Neonatal mortality, Determinants, Border region

\section{Background}

The international border between Brazil, Paraguay, and Argentina is an area that includes Foz do Iguassu (Brazil), Ciudad del Este (Paraguay) and Puerto Iguazú (Argentina). Two international bridges connect these cities: the Tancredo Neves bridge, which connects Foz do Iguassu to Puerto Iguazu, and the Friendship International Bridge, which connects Foz do Iguassu to Ciudad del Este. Altogether, this is the most populous Brazilian border and

\footnotetext{
* Correspondence: fernando.nampo@unila.edu.br

${ }^{1}$ Latin-American Institute of Life and Nature Sciences, Federal University of Latin-American Integration, 1000 Tarquínio Joslin dos Santos Ave ZIP, Foz do Iguassu, PR 85870-650, Brazil

${ }^{3}$ Evidence-Based Public Health Research Group, 1000 Tarquínio Joslin dos Santos Ave ZIP, Foz do Iguassu, PR 85870-650, Brazil

Full list of author information is available at the end of the article
}

covers a contingent of approximately 900,000 inhabitants, of which 264,044 live in Foz do Iguassu [1].

In Brazil, access to healthcare is granted by the Unified Health System (Sistema Único de Saúde - SUS), which provides care to all people in Brazil regardless of nationality and country of residence free of charge, differently than Argentina and Paraguay. Thus, the cross-border movement of patients between the three countries occurs mostly toward Brazil [2], which means that the health indicators found in Foz do Iguassu reflect in some way the healthcare available in the region.

The Infant Mortality Rate (IMR) quantifies the deaths of children under 1 year of age and is a classic indicator of the socioeconomic and health status of the population [3]. The IMR is divided into three periods: the early

(C) The Author(s). 2019 Open Access This article is distributed under the terms of the Creative Commons Attribution 4.0 International License (http://creativecommons.org/licenses/by/4.0/), which permits unrestricted use, distribution, and 
neonatal (death occurred within the first 7 days postpartum); late neonatal (death occurred from 8 to 27 days postpartum) and postneonatal (death occurred from 28 to 365 days postpartum). Brazil has made remarkable progress in facing child mortality, reducing IMR from $51 / 1000$ in 1990 to $15 / 1000$ live births in 2015 [4]. However, the current challenge is to minimize the Neonatal Mortality Rate (NMR) [5], which occurrence highlights the quality of prenatal care, childbirth, and newborn assistance [6] [7]. Although neonatal deaths worldwide account for $44 \%$ of the deaths in children under five [3, 8], in Foz do Iguassu, it represents 61\% of those deaths [9].

The determinants of neonatal mortality are multiple and represent a complex interaction with sociodemographic, healthcare, and biological variables. For this reason, many authors have used a conceptual framework to explain how the interaction between several factors can result in death. Mosley and Chen [10] were pioneers in the application of this model to the study of child survival in developing countries. The framework is based on the premise that all sociodemographic and economic determinants of mortality necessarily operate through a standard set of biological mechanisms, or proximate determinants, to exert an impact of mortality. Thus, through a hierarchical structure, it is possible to consider and model distinct factors according to their precedence over time and their relevance to the outcome determination. The framework can be structured based on the context in which the outcome is studied, and variables can be allocated as many levels as needed to explain the outcome.

Despite the fact that the large proportion of neonatal deaths in Foz do Iguassu, its determinants remain unknown. Undoubtedly the lack of knowledge regarding the determinants of neonatal deaths precludes the diminishment of its occurrence or, at least, reduces the efficiency of actions promoted to decrease NMR. Furthermore, the better comprehension of the causes of newborn mortality at the most populated Brazilian international border may subsidize discussions about the challenges and possibilities of infantile healthcare in other international border areas within this country. Thus, this study aimed to identify the determinants of neonatal mortality in the Brazilian side of the BrazilParaguay-Argentina triple border from 2012 to 2016.

\section{Methods}

\section{Study design}

To identify the factors associated with neonatal death, we performed a case-control study.

\section{Setting}

The study was conducted in Foz do Iguassu, with data from the period 2012 to 2016 . The data were requested from the Municipal Health Department and delivered in Microsoft $^{\circ}$ Excel $^{\circ}$ spreadsheets.

\section{Participants}

Cases were defined as all neonates who died within the first 27 days of life while controls were selected among those who survived the first 27 days of life. Neonates with a birth weight of fewer than $500 \mathrm{~g}$ or born before 24 gestational weeks were excluded. Four controls were matched to each case based on the date of birth.

\section{Data source}

The Brazilian government implemented two health information systems to surveil the mortality and birth conditions, the Information System on Live Births (Sistema de Informação Sobre Nascidos Vivos - SINASC) in 1990 and the Information System on Mortality (Sistema de Informação Sobre Mortalidade - SIM) in 1975, respectively. All births and deaths occurring in Brazil, regardless of maternal nationality or living place, must be registered by filling out the "Declaration of Live Birth" and "Declaration of Death", which populate the corresponding databases. Together, SINASC and SIM provide information that enables the construction of useful indicators for the management of health services in Brazil. The information gathered through these health information systems, which include maternal sociodemographic characteristics, information on pregnancy care and newborn characteristics, instigated the increase in research about maternal and child health in Brazil [11] [12].

Data used for the current study were extracted from SIM and SINASC databases. All neonatal deaths occurred in Foz do Iguassu from 2012 to 2016 were retrieved. The data were delivered in electronic spreadsheets individualized per year of occurrence and were later compiled into a single database for both SIM and SINASC.

To identify the births that evolved to neonatal death, we performed a probabilistic linkage to match SIM and SINASC registries. The use of linkage presupposes the existence of information recorded in standardized and individualized documents to allow the identification of the same individual in two or more databases. In this study, the linkage allowed us to merge the information contained in SIM and SINASC databases regarding maternal sociodemographic characteristics, information on pregnancy care, and newborn characteristics. The variables used to link the SIM and SINASC were the "Declaration of Live Birth" unique registry number, mother's full name, birth date, and birth weight. The linkage was performed using Link Plus 2.0 software. Link Plus is a probabilistic record linkage program developed at CDC's Division of Cancer Prevention and Control in support of CDC's National Program of Cancer Registries (NPCR). 
Although designed to be used by cancer registries, this program can be used with any data in different contexts.

\section{Conceptual framework}

Based on other studies [13] [14], we modified the conceptual framework to our setting (Fig. 1) based on the available information in SIM and SINASC. We allocated the variables at three levels:

i. distal level: those variables inherent to the mother and more unlikely to be altered;

ii. intermediate level: those variables that may be affected by the distal level but at the same time may undergo interventions that may impact the outcome;

iii. proximal level: those variables related to the newborn that may Despite the fact that the outcome, and some of these variables may reflect the distal and intermediate levels.

\section{Variables}

The information extracted from the databases and used in the conceptual framework included: Maternal age (less than 20 years (i.e. adolescent pregnancy), 20 to 34 years or more than 34 years (i.e. advanced maternal age)); mother's education (up to 7 years of study, 8 to 11 years of study or $>12$ years of study); marital status (with a partner or without a partner); race (white, yellow, black and brown); parity (primiparous or multiparous); onset of prenatal care (first trimester or after the first trimester); prenatal care appointments (0 to 3 appointments, 4 to 6 appointments or 7 or more appointments); induction of delivery (yes or not); mode of delivery (vaginal or cesarean section); gestational age, which is measured by the date of the last menstrual period, either by ultrasonography or both (preterm (up to 36 weeks), term (from 37 to 41 weeks) or post-term (42 weeks or more)); sex (male or female); birth weight (low weight (less than $2500 \mathrm{~g}$ )), adequate weight (2500-4000 g) or overweight (more than $4000 \mathrm{~g}$ )); fetal congenital anomaly (yes or no); first minute Apgar score (low (from 0 to 6 points) or high (from 7 to 10 points)).

As a remark, we merged the race 'yellow' with the race 'white' in the logistic model due to sample power.

\section{Statistical analyses}

A multiple logistic regression model with hierarchical input of the variables in blocks was performed to verify

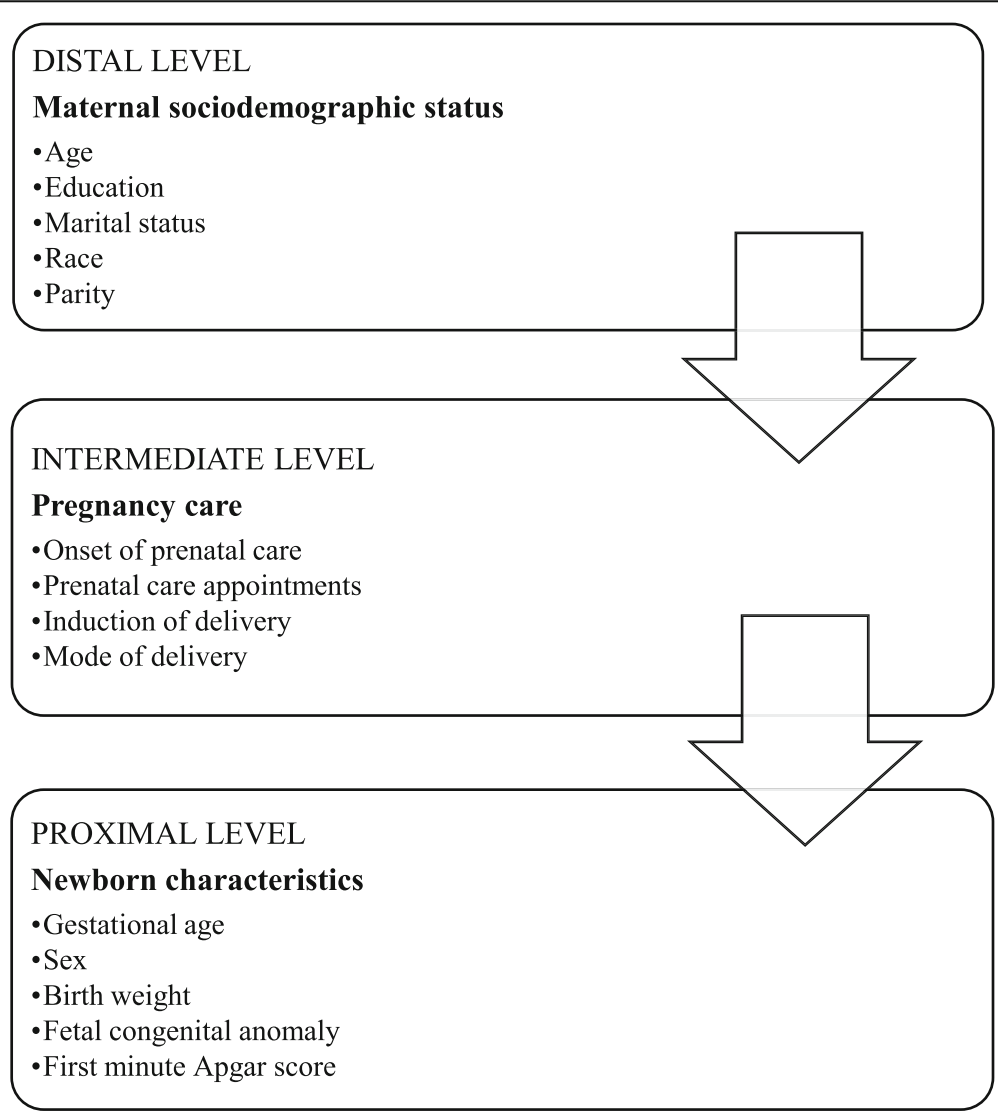

Fig. 1 Conceptual framework for determinants of neonatal mortality in Foz do Iguassu 
the factors associated with neonatal mortality (Fig. 1). The Odds Ratio (OR) and 95\% Confidence Intervals $(95 \% \mathrm{CI})$ were calculated for each variable. In the final logistic regression model, the OR was adjusted for all the selected variables within that level and the variables of farther levels. In other words, at the distal level the OR of the maternal age, mother's education, marital status, race and parity variables, were adjusted for each other; while at the intermediate level, the OR of the onset of prenatal care, prenatal care appointments, induction of delivery and mode of delivery variables, were adjusted for each other and for the independent variables of the distal level. Finally, at the proximal level, the OR of the gestational age, sex, birth weight, fetal congenital anomaly, and first minute Apgar score variables, were adjusted for each other and for the independent variables of both the intermediate and distal level.

The pairing process and statistical analyses were conducted using STATA 13.1 (Stata-Corp, College Station, TX, USA).

\section{Results}

From 2012 to 2016, 25,563 births were registered in Foz do Iguassu, with an IMR of 15.45/1000 live births $(N=$ 395). Overall, neonatal mortality counted for $71 \%(N=$ 280) of the infant deaths and represented an NMR of $10.95 / 1000$ live births. Most of the neonatal deaths $(65.9 \% ; N=147)$ occurred in the early neonatal period (i.e. within the first 7 days after delivery).

From the linkage between SIM and SINASC databases, 250 of the 280 "Declaration of Death" were successfully linked to their respective "Declaration of Live Birth". After linkage, 19 birth records with gestational age less than 24 weeks and another 8 registries of birth weight lower than $500 \mathrm{~g}$ were excluded. The remaining 223 cases were paired with 889 controls that also met the inclusion criteria of gestational age and birth weight.

Among the distal level variables (i.e. maternal sociodemographics), cases, and controls presented quite similar characteristics on maternal age, education level, marital status, and race. In intermediate level (i.e. pregnancy care), the cases presented a higher frequency of prenatal care starting after the first trimester $(22.4 \%$ versus $15.9 \%$ ), pregnancies with zero to 3 prenatal care appointments (26.6\% versus 6.8\%), induction of delivery (79.7\% versus $56.4 \%$ ) and cesarean section (61\% versus $56.7 \%$ ). In the proximal level (i.e. newborn characteristics), the cases presented a higher occurrence of preterm newborn (49.7\% versus $11 \%)$, low birth weight $(72.2 \%$ versus $0.59 \%)$, fetal congenital anomaly (21.1\% versus $1.2 \%)$ and low Apgar score (64.7\% versus 5.2\%) (Table 1).

The multiple logistic regression using the conceptual framework revealed no maternal sociodemographic characteristics associated with neonatal death. Among the pregnancy care variables, induction of delivery that was associated with neonatal mortality in the logistic regression by blocks lost strength in the final model. Only the number of prenatal care appointments remained statistically associated with neonatal death (zero to 3 appointments; OR 3.34; CI 95\% 1.28-8.73; $p=0.014$ ). Most of the newborn's characteristics were associated with neonatal death; except for the sex, all newborn's characteristics presented a strong statistical association with neonatal mortality. Fetal congenital anomaly presented the strongest statistical association with neonatal death (OR 22.49; CI 95\% 7.44-67.95; $p=<0.001$ ), followed by low birth weight (OR 17.15; CI 95\% 8.56-34.37; $p=<$ 0.001), low first minute Apgar score (OR 15.60; CI 95\% 8.23-29.67; $p=<0.001$ ), and prematurity (OR 3.60; CI 95\% 1.87-7.11; $p=<0.001$ ) (Table 2).

\section{Discussion}

According to our literature review, this study is the most comprehensive investigation regarding factors associated with neonatal mortality in an international border region. Previous studies in the Brazilian border region focused on the causes of infant mortality, including only Brazilian resident mothers [15] [16]. We opted to include all deaths, without distinction of maternal domicile, because the assistance to foreigners can affect the provision of services to the local population and also impacts the health indicators in the municipality. Additionally, the public health services in Foz do Iguassu impose several barriers to foreigners (e.g. preventing foreign patients from accessing the health services [2]), which is illegal and instigate the foreigners to falsely affirm that they live in Brazil; thus, the identification of the pregnant who live in Brazil would be imprecise. Moreover, our study focused on neonatal mortality because it is the main component of IMR and is the current challenge to reduce infant mortality [5].

In our investigation, the occurrence of congenital fetal anomaly presented the strongest statistical association with neonatal death, followed by low birth weight, low first minute Apgar score, zero to 3 prenatal appointments and preterm birth. As expected, our results indicated that the newborn's characteristics are the most proximately related to neonatal mortality. Of note, all the statistically associated risk factors presented a moderate/strong association with neonatal death, with three of the five risk factors showing an OR above 15 [17].

There is consensus on the importance of prenatal care to minimize the risk of adverse outcomes for the mother and newborn [18] [19] [20]. The Parana's Mother Network (Rede Mãe Paranaense) Program, a strategy implemented in the state of Parana, recommends seven prenatal appointments, preferably starting in the first trimester [19]. In the present study, only $39.5 \%$ of the cases 
Table 1 Characteristics of cases $(N=223)$ and controls $(N=889)$. Foz do Iguassu PR, 2012-2016

\begin{tabular}{|c|c|c|}
\hline Variable & $\begin{array}{l}\text { Cases } \\
\mathrm{N}(\%) \\
\end{array}$ & $\begin{array}{l}\text { Controls } \\
\mathrm{N}(\%)\end{array}$ \\
\hline \multicolumn{3}{|l|}{ Distal Level } \\
\hline Maternal age [mean (SD)] & $26.6(7.2)$ & $26.7(6.6)$ \\
\hline Less than 19 years & $44(19.7)$ & $130(14.6)$ \\
\hline From 20 to 34 years & $144(64.6)$ & $639(71.9)$ \\
\hline Over 35 years & $35(15.7)$ & $120(13.5)$ \\
\hline \multicolumn{3}{|l|}{ Education (in years of study) } \\
\hline Less than 7 years & $10(4.5)$ & $35(3.9)$ \\
\hline From 8 to 11 years & $44(19.7)$ & $174(19.6)$ \\
\hline Over 12 years & $169(75.8)$ & $679(76.4)$ \\
\hline \multicolumn{3}{|l|}{ Marital status } \\
\hline With partner & $101(45.5)$ & $448(50.6)$ \\
\hline Without partner & $121(54.5)$ & $437(49.4)$ \\
\hline \multicolumn{3}{|l|}{ Race } \\
\hline White & $144(64.6)$ & $546(61.7)$ \\
\hline Black & $6(2.7)$ & $19(2.2)$ \\
\hline Yellow & $0(0)$ & $8(0.9)$ \\
\hline Brown & $73(32.7)$ & $321(35.2)$ \\
\hline \multicolumn{3}{|l|}{ Parity } \\
\hline Primiparous & $95(42.6)$ & $346(39)$ \\
\hline Multiparous & $128(57.4)$ & $540(61)$ \\
\hline \multicolumn{3}{|l|}{ Intermediate level } \\
\hline \multicolumn{3}{|l|}{ Onset of prenatal care } \\
\hline First trimester & $152(77.6)$ & $742(85.1)$ \\
\hline After first trimester & $44(22.4)$ & $129(15.9)$ \\
\hline \multicolumn{3}{|l|}{ Prenatal care appointments } \\
\hline From 0 to 3 appointments & $58(26.6)$ & $60(6.8)$ \\
\hline From 4 to 6 appointments & $74(33.9)$ & $210(23.7)$ \\
\hline 7 or more appointments & $86(39.5)$ & $615(69.5)$ \\
\hline \multicolumn{3}{|l|}{ Induction of delivery } \\
\hline No & $44(20.3)$ & $384(43.6)$ \\
\hline Yes & $173(79.7)$ & $497(56.4)$ \\
\hline \multicolumn{3}{|l|}{ Type of delivery } \\
\hline Vaginal & $87(39)$ & $385(43.3)$ \\
\hline Caesarean section & $136(61)$ & $504(56.7)$ \\
\hline \multicolumn{3}{|l|}{ Proximal level } \\
\hline \multicolumn{3}{|l|}{ Gestational age } \\
\hline Preterm & $148(49.71)$ & $94(11)$ \\
\hline Term & $64(30.2)$ & $732(85.6)$ \\
\hline Post-term & $0(0)$ & $29(3.40)$ \\
\hline \multicolumn{3}{|l|}{ Sex } \\
\hline Female & $103(46.6)$ & $424(47.4)$ \\
\hline Male & $118(53.4)$ & $465(52.3)$ \\
\hline
\end{tabular}

Birth weight
Table 1 Characteristics of cases $(N=223)$ and controls $(N=889)$. Foz do Iguassu PR, 2012-2016 (Continued)

\begin{tabular}{lll}
\hline Variable & $\begin{array}{l}\text { Cases } \\
\mathrm{N}(\%)\end{array}$ & $\begin{array}{l}\text { Controls } \\
\mathrm{N}(\%)\end{array}$ \\
\hline Low weight & $161(72.2)$ & $52(0.59)$ \\
Adequate weight & $59(26.4)$ & $783(88.1)$ \\
Overweight & $3(0.1)$ & $54(0.6)$ \\
Fetal congenital anomaly & & $11(1.2)$ \\
Yes & $47(21.1)$ & $878(98.8)$ \\
No & $176(78.9)$ & \\
First minute Apgar score & & $841(94.8)$ \\
High & $77(35.3)$ & $46(5.2)$ \\
Low & $141(64.7)$ &
\end{tabular}

performed the minimum number of recommended prenatal appointments, against $69.5 \%$ of the controls; however, caution is suggested in interpreting this result, because the low number of prenatal appointments may be associated with pregnancies of less than 30 weeks that would prevent the occurrence of 7 or more appointments. Births before the completion of 30 gestational weeks were more frequent among cases (42\%) than among controls $(0.3 \%)$.

The Apgar score shows the physiological conditions and responsiveness of the newborn to extrauterine life and has been used for more than 50 years as an useful and lowcost tool that remains relevant to contemporary practice in predicting the risk of newborn death and, consequently, to identify those who need additional care in the neonatal and post-neonatal period [21] [22]. The first minute Apgar score below 7 was statistically associated with neonatal mortality in our study and half of the deaths also presented low Apgar score, corroborating other studies [23] [24] [25]. Despite being considered an endpoint, the low Apgar score precedes death and can be prevented, especially with adequate attention to pregnant women. We believe that Intrapartum asphyxia demands specific attention during delivery and the prevention of problems related to intrauterine hypoxia and timely interventions may decrease the risk of death due to intrapartum asphyxia in Brazil, considering that almost $100 \%$ of births occur in health institutions [5] [26].

Prematurity is one of the leading causes of child death in the world [27] [28]. The gestational age, which was statistically associated with neonatal mortality in this study, is a relevant factor because it is associated with low birth weight, incomplete fetal development, and low Apgar score. The supply of oxygen through the placenta increases with the course of gestation according to the fetal needs [21] [24]; a premature birth interrupts this process, exposing the newborn to oxygen deprivation, which can be harmful to the tissues, especially the 
Table 2 Factors associated with neonatal mortality based on conceptual framework analysis (distal, intermediate, and proximal factors). Foz do Iguassu PR, 2012-2016

\begin{tabular}{|c|c|c|c|c|c|c|}
\hline Variable & OR & $\mathrm{Cl} 95 \%$ & $p$-value & Adjusted OR & Cl 95\% & $p$-value \\
\hline \multicolumn{7}{|l|}{ Distal Level } \\
\hline \multicolumn{7}{|l|}{ Maternal age } \\
\hline Less than 19 years & 1.49 & $0.99-2.32$ & 0.053 & 1.04 & $0.45-2.41$ & 0.921 \\
\hline From 20 to 34 years & 1.00 & - & - & 1.00 & - & - \\
\hline Over 35 years & 1.23 & $0.79-1.93$ & 0.349 & 0.95 & $0.43-2.11$ & 0.905 \\
\hline \multicolumn{7}{|l|}{ Education (years of study) } \\
\hline Less than 7 years & 1.03 & $0.70-1.54$ & 0.846 & 1.12 & $0.53-2.34$ & 0.766 \\
\hline From 8 to 11 years & 1.12 & $0.49-2.53$ & 0.779 & 0.85 & $0.17-4.11$ & 0.8 \\
\hline Over 12 years & 1.00 & - & - & 1.00 & - & - \\
\hline \multicolumn{7}{|l|}{ Marital status } \\
\hline With partner & 1.00 & - & - & 1.00 & - & - \\
\hline Without partner & 1.19 & $0.88-1.63$ & 0.249 & 0.70 & $0.40-1.24$ & 0.226 \\
\hline \multicolumn{7}{|l|}{ Race } \\
\hline White & 1.00 & - & - & 1.00 & - & - \\
\hline Black & 1.16 & $0.48-3.10$ & 0.519 & 0.91 & $0.16-5.20$ & 0.912 \\
\hline Brown & 0.90 & $0.66-1.23$ & 0.681 & 0.90 & $0.50-1.64$ & 0.742 \\
\hline \multicolumn{7}{|l|}{ Parity } \\
\hline Primiparous & 1.00 & - & - & 1.00 & - & - \\
\hline Multiparous & 1.20 & $0.76-1.88$ & 0.424 & 1.44 & $0.76-2.70$ & 0.261 \\
\hline \multicolumn{7}{|l|}{ Intermediate level } \\
\hline \multicolumn{7}{|l|}{ Onset of prenatal care } \\
\hline First trimester & 1.00 & - & - & 1.00 & - & - \\
\hline After first trimester & 0.91 & $0.58-2.84$ & 1.44 & 1.33 & $0.63-2.84$ & 0.448 \\
\hline \multicolumn{7}{|l|}{ Prenatal care appointments } \\
\hline 0 to 3 appointment & $6.76^{*}$ & $3.89-11.73$ & $<0.001$ & $3.34^{*}$ & $1.28-8.73$ & 0.014 \\
\hline 4 to 6 appointments & $2.63^{*}$ & $1.78-3.88$ & $<0.001$ & 1.17 & $0.60-2.27$ & 0.640 \\
\hline 7 or more appointments & 1.00 & - & - & 1.00 & - & - \\
\hline \multicolumn{7}{|l|}{ Induction of delivery } \\
\hline No & $3.84^{*}$ & $2.32-6.36$ & $<0.001$ & 0.64 & $0.30-1.38$ & 0.264 \\
\hline Yes & 1.00 & - & - & 1.00 & - & - \\
\hline \multicolumn{7}{|l|}{ Type of delivery } \\
\hline Vaginal & 1.00 & - & - & 1.00 & - & - \\
\hline Caesarean section & 0.77 & $0.49-1.23$ & 0.289 & 1.83 & $0.88-3.80$ & 0.106 \\
\hline \multicolumn{7}{|l|}{ Proximal level } \\
\hline \multicolumn{7}{|l|}{ Gestational age } \\
\hline Preterm & $3.45^{*}$ & $1.86-6.39$ & $<0.001$ & $3.64^{*}$ & $1.87-7.11$ & $<0.001$ \\
\hline Term & 1.00 & - & - & 1.00 & - & - \\
\hline Post-term & - & - & - & - & - & - \\
\hline \multicolumn{7}{|l|}{ Sex } \\
\hline Female & 1.08 & $0.65-1.82$ & 0.745 & 0.87 & $0.50-1.52$ & 0.630 \\
\hline Male & 1.00 & - & - & 1.00 & - & - \\
\hline \multicolumn{7}{|l|}{ Birth weight } \\
\hline Low & $18.34^{*}$ & $9.73-34.55$ & $<0.001$ & $17.15^{*}$ & $8.55-34.37$ & $<0.001$ \\
\hline
\end{tabular}


Table 2 Factors associated with neonatal mortality based on conceptual framework analysis (distal, intermediate, and proximal factors). Foz do Iguassu PR, 2012-2016 (Continued)

\begin{tabular}{|c|c|c|c|c|c|c|}
\hline Variable & OR & Cl 95\% & $p$-value & Adjusted OR & Cl 95\% & $p$-value \\
\hline Adequate & 1.00 & - & - & 1.00 & - & - \\
\hline Overweight & 0.93 & $0.21-4.06$ & 0.928 & 0.98 & $0.22-4.44$ & 0.994 \\
\hline \multicolumn{7}{|c|}{ Fetal congenital anomaly } \\
\hline Yes & $22.66^{*}$ & $8.78-58.47$ & $<0.001$ & $22.49^{*}$ & $7.44-67.95$ & $<0.001$ \\
\hline No & 1.00 & - & - & 1.00 & - & - \\
\hline \multicolumn{7}{|c|}{ First minute Apgar score } \\
\hline High & 1.00 & - & - & 1.00 & - & - \\
\hline Low & $14.51^{*}$ & $8.06-26.10$ & $<0.001$ & $15.63^{*}$ & $8.23-29.67$ & $<0.001$ \\
\hline
\end{tabular}

* Variables statistically associated with neonatal death

nervous system [29], increasing the risk of cerebral palsy, visual disturbances and chronic disease in adulthood [30]. Consequently, a premature newborn increases intensive care expenses, and also affects the family's social, financial, and emotional status. Therefore, investing in prenatal care, focusing on the identification of pregnancies at risk of prematurity may reduce both the financial burden and the social impact of this event.

For this study, all congenital anomalies recorded in SINASC were included according to their code of Chapter 17 of the 10th International Classification of Diseases. The strong association between congenital fetal anomaly and neonatal death observed in this study corroborates the evidence found in other studies [12] [19]. Congenital anomalies contribute significantly to premature birth, morbidity, and neonatal mortality. Since the improvement of healthful conditions and the reduction of infant deaths due to infectious and parasitic diseases, the anomalies became an important risk factor associated to IMR, evidencing the process of epidemiological transition that most countries experience. According to an a posteriori analysis, most newborns with congenital anomalies were born at normal gestational age (76\%) and normal birth weight (78\%). Therefore, the only risk factor considered to be unavoidable seems not to be related to prematurity and low birth weight, indicating that it may be possible to reduce neonatal mortality by acting on avoidable risk factors [31].

Maternal sociodemographic factors can impact childcare, not only about access to health services but also living conditions, basic sanitation, and nutrition [32]. Although previous studies have shown negative effects of maternal age and education on perinatal outcomes [33] [34], in our study, those variables were not associated with neonatal mortality. The lack of association between maternal sociodemographic characteristics and neonatal death may be related to the fact that two-thirds of the deaths occurred in the early neonatal period when most mothers and newborns are being assisted in hospitals, suggesting poor healthcare provided in the early postpartum period, regardless of sociodemographic characteristics. At least partially, this poor healthcare provided in the early neonatal period may be related to hospital overload. In Foz do Iguassu, the only hospital with a Neonatal Intensive Care Unit (NICU) is a reference for maternity to 9 municipalities within western Parana; additionally, it receives pregnant women and newborns from neighboring countries. Nevertheless, at the end of this research, the hospital had only 18 intensive or intermediate care unit beds, which is $25 \%$ below the established by the Brazilian Ministry of Health.

In an a posteriori investigation, we found that the rates of prematurity, low birth-weight, low first minute Apgar score, and congenital anomaly incidence are not worse than those found in Parana state and Brazil. In contrast, Foz do Iguassu presents twice the rate of unsatisfactory prenatal appointments in comparison to Parana state and Brazil. Thus, the high rates of neonatal deaths in this region possibly translate the poor quality of the local health services.

Although some variables of the proximal level, such as Apgar score, birth-weight, and prematurity, are considered endpoints, we understand that they precede death and reflect distal and intermediate level variables, being relevant in the model constructed for this study. Besides, they are risk factors for neonatal death already established in the literature. With this in mind, we proposed the analysis of these risk factors through the conceptual framework, which analyzes the effect of each variable on neonatal death hierarchically mediated by the other variables.

We acknowledge some limitations in this research. Firstly, as every study that relies on secondary data analysis, missing or incorrect information is an inherent risk. Also, the official databases used in our research do not provide information on maternal diseases, which may also be associated with neonatal mortality. Regarding the strengths of the study, to improve the reliability of our data, we performed an a priori data completeness analysis for the period from 1996 to 2016. Considering 
the high frequency of missing data before 2012 and the modifications in the data gathered through SINASC in 2011, we analyzed only births occurred from 2012 to 2016. Besides, the choice of analysis through the conceptual framework allowed us to model different factors according to their precedence over time and their relevance to the outcome determination; moreover, this analysis model represents a strategy for dealing with a large number of conceptually related variables present in epidemiological studies.

\section{Conclusion}

Fetal congenital anomaly, low birth-weight, low first minute Apgar score, zero to 3 prenatal appointments, and prematurity are associated with neonatal death. At the largest international border of Brazil, the maternal sociodemographic condition is not associated with neonatal mortality. The implications for practice that may be derived from our study is that health services need to (i) increase the prenatal surveillance and (ii) pay attention to its in-patient care for pregnant women and newborns. Finally, based on our findings, we recommend that future research investigates (i) the quality of prenatal care, childbirth and early postpartum attention, (ii) the risk factors associated with prematurity, (iii) the impact of cross-border patients on childbirth indicators and (iv) the epidemiology of congenital anomaly in this international border.

\section{Abbreviations}

IMR: Infant Mortality Rate; NICU: Neonatal Intensive Care Unit; NMR: Neonatal Mortality Rate; SIM: Information System on Mortality (Sistema de Informação de Mortalidade); SINASC: Information System on Live Births (Sistema de Informação de Nascidos Vivos)

\section{Acknowledgments}

Not applicable.

\section{Authors' contributions}

SS contributed to the conception and design, acquisition and interpretation of data and drafting of the manuscript. ED contributed to the design, data analysis, and revising the manuscript. FKN contributed to the conception, design, and data interpretation, and was the major contributor in revising the manuscript. All authors read and approved the final manuscript.

\section{Funding}

This research was funded by the Araucaria Foundation, through a scholarship granted to SS during the research.

\section{Availability of data and materials}

The datasets analyzed during the current study are not publicly available due to the privacy policy imposed by the Brazilian government but may be available from the corresponding author on reasonable request.

\section{Ethics approval and consent to participate}

This research was approved by the Human Research Ethics Committee of the Western Paraná University; evaluation number: 1,838,369; Certified Ethical Presentation number: 55944816.5.0000.0107.

\section{Consent for publication}

Not applicable.

\section{Competing interests}

The authors declare that they have no competing interests.

\section{Author details}

'Latin-American Institute of Life and Nature Sciences, Federal University of Latin-American Integration, 1000 Tarquínio Joslin dos Santos Ave ZIP, Foz do Iguassu, PR 85870-650, Brazil. ${ }^{2}$ School of Public Health, Department of Epidemiology, University of Sao Paulo, 715 Dr. Arnaldo Ave ZIP, São Paulo, SP 01246-000, Brazil. ${ }^{3}$ Evidence-Based Public Health Research Group, 1000 Tarquínio Joslin dos Santos Ave ZIP, Foz do Iguassu, PR 85870-650, Brazil.

Received: 26 June 2019 Accepted: 16 September 2019

Published online: 16 October 2019

\section{References}

1. IPARDES. Foz do Iguassu's Statistics. 2018. http://www.ipardes.gov.br/ cadernos/MontaCadPdf1.php? Municipio=85850. Accessed 22 May 2018.

2. Lima R. The right to the health and access to sus: restrictions imposed on the foreign population of the triple borderland. Direito sem fronteiras. 2017;1563:61-77.

3. Liu L, Johnson HL, Cousens S, Perin J, Scott S, Lawn JE, et al. Global, regional, and national causes of child mortality: an updated systematic analysis for 2010 with time trends since 2000. Lancet. 2012;379:2151-61.

4. UNICEF, WHO. Levels \& Trends in Child Mortality. Report 2015. 2015;:1-34. http://www.who.int/maternal_child_adolescent/documents/levels_trends_ child_mortality_2015/en/.

5. Lansky S, Friche AA de L, Silva AAM da, Campos D, Bittencourt SD de A, Carvalho ML de, et al. Birth in Brazil survey: neonatal mortality profile, and maternal and child care. Caderno de Saúde Pública. 2014;30 Sup:S192-S207.

6. de Carvalho M, Gomes MASM. Mortality of very low birth weight preterm infants in Brazil: reality and challenges. J Pediatr. 2005;81(1 Suppl):S111-8.

7. Gatt M, England K, Grech V, Calleja N. Contribution of congenital anomalies to neonatal mortality rates in Malta. Paediatr Perinat Epidemiol. 2015;29:401-6.

8. Carlo WA, Travers CP. Maternal and neonatal mortality: time to act. J Pediatr. 2016;92:543-5.

9. Brasil. Vital statistics Data SUS. 2017. http://www2.datasus.gov.br/DATASUS/ index.php?area $=0205 \& i d=6937$.

10. Mosley WH, Chen LC. An Analytical Framework for the Stuy of Child Survival in Developing Countries 1984;81.

11. Schoeps D, de Almeida MF, Alencar GP, França I Jr, Novaes HMD, de Siqueira AAF, et al. Risk factors for early neonatal mortality. Rev Saude Publica. 2007;41:1013-22.

12. Santa Helena E, Sousa C, Amorin C. Risk factors for neonatal mortality in Blumenau, Santa Catarina: linkage between database. Revista Brasileira de Saúde Materno Infantil. 2005;5:209-2017.

13. Martins EF, Velásquez-Meléndez G. Determinants of neonatal mortality in a cohort of born alive infants, Montes Claros, Minas Gerais, 1997-1999. Revista Brasileira de Saúde Materno Infantil 2004:4:405-412.

14. Do NRM, ÁJM L, De ANMGS, De APC, Da SCF. Determinants of neonatal mortality: a case-control study in Fortaleza, Ceará State, Brazil. Cadernos de Saúde Pública. 2012;28:559-72.

15. Doldan RV, da Costa JSD, Nunes MF. Associated factors and infant mortality in the municipality of Foz Do Iguaçu, state of Paraná, Brazil - a case control study. Epidemiologia e Serviços de Saúde. 2011;20:491-8.

16. Mombelli MA, Sass A, Molena CAF, Téston EF, Marcon SS. Risk factors for child mortality in towns of Paraná state (South Brazil), from 1997 to 2008. Revista Paulista de Pediatria. 2012;30:187-94.

17. Craun GF. How To Interpret Epidemiological Associations. Environmental Protection. 1979:108-15.

18. Soares ES, Menezes GM de S. Factors associated with neonatal mortality: situation analysis at the local level Enio. Epidemiologia e Serviços de Saúde. 2010;19:51-60.

19. Gaiva MAM, Fujimori E, Sato APS. Maternal and child risk factors associated with neonatal mortality. Texto e Contexto Enfermagem. 2016;25:2-9.

20. Demitto M de O, Gravena AAF, Dell'Agnolo CM, Antunes MB, Pelloso SM, Demitto $M$ de $\mathrm{O}$, et al. High risk pregnancies and factors associated with neonatal death Revista da Escola de Enfermagem da USP 2017;51:1-7.

21. de Oliveira TG, Freire PV, Moreira FT, da SB de Moraes J, Arrelaro RC, Rossi S, et al. Apgar score and neonatal mortality in a hospital located in the southern area of São Paulo City. Brazil Einstein. 2012;10:22-8. 
22. Li F, Wu T, Lei X, Zhang H, Mao M, Zhang J. The Apgar score and infant mortality. PLoS One. 2013;8:1-8.

23. Zamberlan KC, Silveira A, Arrué AM, Neves ET, Borna GG. Factors associated with neonatal morbidity and mortality: a review. Jornla de Saúde de Santa Maria. 2014;40:9-14.

24. Niodromiti S, MacKay DF, Smith GCS, Pell JP, Nelson SM. Apgar score and the risk of cause-specific infant mortality: a population-based cohort study. Lancet. 2014;384:1749-55.

25. Inês A, li S, Harter R, lii G, Primo CC. Risk factors for neonatal mortality in the city of Serra. Espírito Santo Rev Bras Enferm. 2012;65:578-85.

26. Lawn JE, Kinney M, Lee ACC, Chopra M, Donnay F, Paul VK, et al. Reducing intrapartum-related deaths and disability: Can the health system deliver? Int J Gynaecol Obstet. 2009;(107 SUPPL):S123-42.

27. UNICEF. Levels \& Trends in Child Mortality Report 2017. Child Mortality. 2017:1-40. doi:https://doi.org/10.1016/50140-6736(10)60703-9.

28. Sankar MJ, Natarajan CK, Das RR, Agarwal R, Chandrasekaran A, Paul VK. When do newborns die? A systematic review of timing of overall and cause-specific neonatal deaths in developing countries. J Perinatol. 2016; 36(Suppl 1):S1-11.

29. Singh R, Das BK, Shah GS. Outcome of newborns with birth asphyxia. J Nepal Med Assoc. 2005;44:44-6.

30. Mwaniki MK, Atieno M, Lawn JE, Newton CRJC. Long-term neurodevelopmental outcomes after intrauterine and neonatal insults: a systematic review. Lancet. 2012;379:445-52.

31. Malta DC, Duarte EC, Almeida MF, Dias MADS, Neto OLDM, De Moura L, et al. List of avoidable causes of deaths due to interventions of the Brazilian health system. Epidemiologia de Serviços de Saúde. 2007;16:233-44.

32. Bali D, Kuli-lito G, Ceka N, Godo A. Maternal and child health Care Services in Albania. J Pediatr. 2016;177:S11-20.

33. Gravena AAF, De Paula MG, Marcon SS, De Carvalho MDB, Pelloso SM. Maternal age and factors associated with perinatal outcomes. ACTA Paulista de Enfermagem. 2013;26:130-5.

34. De Azevedo GD, Freitas Júnior R, Freitas A, De Araújo ACPF, Soares EMM Maranhão TMDO. Effect of maternal age on perinatal outcomes. Revista Brasileira de Ginecologia e Obstetrícia. 2002;24:181-5.

\section{Publisher's Note}

Springer Nature remains neutral with regard to jurisdictional claims in published maps and institutional affiliations.

Ready to submit your research? Choose BMC and benefit from:

- fast, convenient online submission

- thorough peer review by experienced researchers in your field

- rapid publication on acceptance

- support for research data, including large and complex data types

- gold Open Access which fosters wider collaboration and increased citations

- maximum visibility for your research: over $100 \mathrm{M}$ website views per year

At BMC, research is always in progress.

Learn more biomedcentral.com/submissions 